\title{
NegligênCia Familiar: Implicaçóes na Aprendizagem Escolar DE ESTUdANTES COM DeficiêNCIA VISUAL ${ }^{1}$

\author{
Family NeGLECT: Implications on the SCHOOL LEARNing of Visually \\ IMPAIRED STUDENTS
}

\author{
Lilian Roberta Ilha SACCOL ${ }^{2}$ \\ Clecimara VIANNA ${ }^{3}$ \\ Silvia Maria de Oliveira PAVÃO ${ }^{4}$
}

\begin{abstract}
RESUMO: No âmbito da Educação Especial, o presente artigo procurou compreender as interferências da negligência familiar no que se refere aos processos de aprendizagem de estudantes com deficiência visual. Para tanto, foi realizada uma pesquisa de natureza básica, com abordagem qualitativa. Quanto aos objetivos, o estudo caracterizou-se como exploratório descritivo. O delineamento adotado foi o estudo de caso. Foram empregados, na pesquisa, como instrumentos de produção de dados, sete atas de ocorrências escolares referentes a duas estudantes com deficiência visual e cinco entrevistas focalizadas, a saber: duas entrevistas com as estudantes, duas entrevistas com os professores de classe e uma entrevista com a educadora especial da instituiçáo onde ocorreu a pesquisa. Estes constituíram-se o público-alvo do estudo, que aconteceu no espaço de uma escola pública do interior do Rio Grande do Sul. A análise de conteúdo foi adotada para a interpretação dos dados, apontando a existência de três categorias de análise, quais sejam: negligência familiar, aprendizagem de estudantes com Deficiência Visual e troca de guarda. Como resultado, a negligência familiar destaca-se como um fator que interfere negativa e substancialmente, não só na aprendizagem, mas, sobremaneira, nas atitudes, nas relaçóes interpessoais e nos sentimentos dos que vivem sob essa realidade, especialmente os estudantes com deficiência visual.
\end{abstract}

PALAVRAS-CHAVE: Negligência. Deficiência visual. Aprendizagem. Educação Especial.

\begin{abstract}
In the context of Special Education, this article sought to comprehend the family neglect interference regarding the learning processes of students with visual impairment. For that, a basic research, with a qualitative approach was, carried out. Concerning the objectives, the study was characterized as exploratory descriptive. The adopted design was the case study. In the research, seven school occurrence records regarding two visually impaired students and five focused interviews, namely: two interviews with the students, two interviews with the classroom teacher and one interview with the special educator from the institution where the research took place. These subjects constituted the target audience of this study, which occurred in the space of a public school in the hinterlands of Rio Grande do Sul, Brazil. The content analysis was adopted for data interpretation, pointing out the existence of three categories of analysis, namely: family neglect, learning of visually impaired students and changing custody. As a result, family neglect is highlighted as a factor which interferes negatively and substantially not only in learning but also in attitudes, interpersonal relationship, and feeling of those who live under this reality, especially visually impaired students.
\end{abstract}

KEYWORDS: Negligence. Visual impairment. Learning. Special Education.

\section{INTRODUÇÁO}

...É manhä de inverno e faz muito frio. No intervalo do turno de aula, as crianças correm, brincam, cantam, extravasando toda a energia contida durante a primeira parte dos estudos daquele dia. $O$ cenário até então corriqueiro, diferencia-se pela observação de duas estudantes, próximas, acompanhadas de dois adultos, tateando o universo com bengalas em punho. Säo meninas de 10 anos ou

\footnotetext{
${ }^{1}$ https://doi.org/10.1590/1980-54702021v27e0014

${ }^{2}$ Doutoranda do Programa de Pós-Graduação em Educação da Universidade Federal de Santa Maria (UFSM). Santa Maria/Rio Grande do Sul/Brasil. E-mail: saccollilian@gmail.com. ORCID: https://orcid.org/0000-0002-7863-966X

${ }^{3}$ Mestranda do Programa de Pós-Graduação em Educação - Mestrado Profissional em Políticas Públicas e Gestão Educacional da Universidade Federal de Santa Maria (UFSM). Santa Maria/Rio Grande do Sul/Brasil. E-mail: clecimarav@gmail.com. ORCID: http://orcid.org/0000-0002-5299-0873

${ }^{4}$ Pós-Doutorado - Universidade Federal de Santa Maria (UFSM). Departamento de Fundamentos da Educação. Santa Maria/Rio Grande do Sul/Brasil. E-mail: silvia.pavao@ufsm.br. ORCID: https://orcid.org/0000-0002-5365-0280
} 
mais, com um semblante mais sério que as demais. Vestem poucos agasalhos para um dia tão frio e percebe-se que suas roupas não estão limpas. Uma delas está com a respiração bastante congestionada e limpa o nariz com a manga da blusa. Os cabelos, soltos ao vento, denotam a impressáo de estarem emaranhados e pouco limpos...

Esses são fragmentos de uma cena, que talvez aconteça em muitas outras escolas do Brasil, em que a interpretação pode levar ao que se denomina de negligência. A expressão "negligência” tem um significado associado ao descuido, à depreciação. No Dicionário Online de Língua Portuguesa ${ }^{5}$, encontra-se o significado da palavra "negligência" como falta de cuidado, de interesse, ou, ainda, no seu sentido jurídico, como falta não intencional da pessoa que se omitiu no cumprimento de um ato que lhe foi atribuído.

Com tais sentidos, negligência é um termo que aparece no Art. 227, da Constituição Federal do Brasil (1988), assegurando direitos de crianças e adolescentes quanto à saúde, à alimentação, à educação, ao lazer etc. $\mathrm{O}$ artigo ressalta também o direito à convivência familiar, a salvo de qualquer tipo de violência ou negligência.

A Lei no 8.069, de 13 de Julho de 1990, que dispóe sobre o Estatuto da Criança e do Adolescente (ECA), reforça, em seu Art. $5^{\circ}$, que crianças e adolescentes jamais poderão ser vítimas de negligência, discriminação, exploração, violência, entre outras situaçóes, que serão punidas na forma da lei por quem os desrespeitar.

E, ainda, seu Art. 70 afirma que "é dever de todos prevenir a ocorrência de ameaça ou violação dos direitos da criança e do adolescente" (Lei no 8.069, 1990). Entre as muitas atribuiçóes da escola, além de prover um ensino de qualidade para todos e atender às diferentes demandas educacionais, o ECA, em seu Art. 245, determina que a escola tem o dever de "comunicar à autoridade competente os casos de que tenha conhecimento, envolvendo suspeita ou confirmação de maus-tratos contra criança ou adolescente" (Lei no 8.069, 1990).

Bridi Filho et al. (2018) apontam que, "muitas vezes, as intervenções judiciais são as únicas formas possíveis de resguardo da criança” (p. 184). Assim sendo, é imensa a responsabilidade de gestores e de professores, no sentido de registrar e fazer os devidos encaminhamentos, para assegurar os direitos dos estudantes. Nesse contexto, reconhecer os casos em que as crianças e os adolescentes não têm seus direitos respeitados e sofrem física ou psicologicamente é, também, dever da escola e envolve a observação e a detecção de situaçóes que estejam de alguma forma interferindo na aprendizagem e no bem-estar dos estudantes.

Tais observâncias e encaminhamentos tornam-se ainda mais urgentes quando os envolvidos no descaso e na negligência da família são estudantes com alguma deficiência. Em uma perspectiva inclusiva, a educação "parte do princípio de que todas as diferenças humanas são normais e de que a aprendizagem deve, portanto, ajustar-se às necessidades de cada criança, ao invés de cada criança se adaptar aos pressupostos do processo educativo" (Lima, 2006, p. 11).

A Lei de Diretrizes e Bases da Educação Nacional (Lei n 9.394, de 20 de dezembro de 1996), refere-se, em seu Art. 58, à Educação Especial, como uma "modalidade de educação escolar oferecida preferencialmente na rede regular de ensino, para educandos com deficiên-

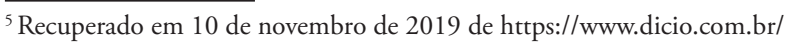


cia, transtornos globais do desenvolvimento e altas habilidades ou superdotação". E assegura, ainda, uma série de direitos que incluem adaptaçóes curriculares, terminalidades específicas, educação para o trabalho e acesso igualitário aos benefícios dos programas sociais. Assim sendo, a escola é o campo onde a maioria desses direitos se consolida. No contexto da Educação Especial, este estudo teve seu foco na deficiência visual.

De acordo com Bruno et al. (2001), pode-se classificar a deficiência visual em: baixa visão, que é a alteração da capacidade funcional da visão, que pode ser decorrente de diversos fatores que interferem ou limitam o desempenho visual do indivíduo - essa limitação da função visual pode ocorrer em diferentes níveis: severo, moderado ou leve, podendo ser influenciada também por fatores ambientais inadequados; e cegueira, que é definida como a ausência total da visão até a perda da projeção de luz.

Para fins educacionais, considera-se cega a pessoa que necessita potencialmente do uso do Braille para a leitura e a escrita. E baixa visão "trata-se de resíduo visual que permite ao educando ler impressos a tinta, desde que se empreguem recursos didáticos e equipamentos especiais" (Lima, 2005, p. 71).

O processo de aprendizagem do estudante cego dar-se-á por meio da integração e da estimulação dos sentidos remanescentes e, principalmente, pelo uso do tato para a leitura da escrita Braille. Para os estudantes com deficiência visual, os recursos e os materiais devem estar de acordo com as necessidades específicas de cada caso (Machado \& Pereira, 2019). Assim sendo, são necessárias adaptaçóes que podem ser compreendidas à luz do Desenho Universal para a Aprendizagem (DUA), que, na área da Educação Especial, visualiza os indivíduos de maneira única e se propóe a pensar nas suas peculiaridades. $\mathrm{O}$ conceito do DUA é baseado na neurociência e defende que cada estudante aprende de determinado modo e por meio de estímulos diversos; desse modo, o DUA é um processo contínuo para pensar no planejamento do ensino (Oliveira et al., 2019).

Assim, o estudante com deficiência visual, tendo seus direitos garantidos com uma escola equitativa, profissionais com formação adequada, atividades adaptadas para suas necessidades, poderá ter um ensino de qualidade e uma aprendizagem satisfatória. No entanto, é preciso apontar, ainda, um agente social de grande importância para que tais resultados sejam atingidos: a família.

Para Buscaglia (2006), "não importa quantos profissionais trabalham com os estudantes com deficiência durante sua vida. Não haverá um que tenha um efeito mais pungente, influente, duradouro e significativo sobre eles do que a família” (p. 127). Desse modo, além de garantir os direitos dos estudantes com deficiência, é preciso certificar-se de que a família cumpre com esse estudante, suas obrigaçóes, para que realmente aconteça uma aprendizagem satisfatória. A família estará em contato contínuo com o indivíduo, ensinando-lhe os costumes e os hábitos da cultura e estipulando regras para o jogo da vida. Com uma influência positiva ou negativa, o primeiro e mais influente terapeuta será sempre a família (Buscaglia, 2006).

Em vista disso, para estudantes com deficiência visual, que vivem sob a égide de uma família negligente, conseguir desenvolver suas habilidades e suas competências para uma aprendizagem satisfatória, é um desafio ainda maior do que vencer suas próprias limitaçóes físicas. 
Assim, no cenário de uma escola pública municipal, no interior do RS, este estudo se atém, por objetivo, a compreender as interferências da negligência familiar relativas aos processos de aprendizagem de estudantes com deficiência visual. Especificamente, empreende-se à compreensão dos aspectos da negligência familiar e suas implicações no contexto escolar, no modo que a negligência familiar interfere na aprendizagem dos estudantes com deficiência visual (DV).

Nesse sentido, o estudo coloca em voga a tríade família, deficiência visual e aprendizagem, levantando discussóes importantes e urgentes no cenário da educação.

\section{Método}

Para atingir o objetivo de compreender as interferências da negligência familiar no que se refere aos processos de aprendizagem de estudantes com deficiência visual, este estudo foi conduzido nos parâmetros metodológicos descritos a seguir.

\subsection{Delineamento}

Buscando responder à questão de pesquisa: De que modo a negligência familiar interfere na aprendizagem de estudantes com deficiência visual?, o delineamento adotado foi o estudo de caso. Para Gil (2014), o estudo de caso é o delineamento de pesquisa que permite o estudo profundo e exaustivo de um ou mais objetos, permitindo seu amplo e detalhado conhecimento. Em Yin (2015), encontra-se a conceituação desse método, como sendo uma pesquisa em profundidade, em que o fenômeno estudado é o "caso" e exige a triangulação a partir de fontes múltiplas de evidências.

\subsection{Participantes}

A pesquisa aconteceu em uma escola da rede pública municipal do Rio Grande do Sul, localizada em uma comunidade carente, cujos estudantes, em maioria, estão em risco de vulnerabilidade social. O estudo contou com três perfis distintos de sujeitos público-alvo, quais sejam: duas meninas, irmãs, estudantes do Ensino Fundamental com DV; dois professores regentes de classe; e uma educadora especial da mesma instituição de ensino.

Para fins éticos, os sujeitos serão tratados, neste estudo, por: Estudante 1, Estudante 2, Professor 1, Professor 2 e Educadora Especial. Os Quadros 1 e 2 trazem as características desses sujeitos.

\section{Quadro 1}

Perfil dos estudantes com deficiência visual

\begin{tabular}{|l|l|l|l|}
\hline Participante & Idade & Ano escolar & Histórico \\
\hline Estudante 1 & 10 anos & $4^{\circ}$ ano - Ensino Fundamental 1 & Sem reprovaçóes \\
\hline Estudante 2 & 12 anos & $5^{\circ}$ ano - Ensino Fundamental 1 & $\begin{array}{l}\text { Reprovada em 2018 no 50 } \\
\text { ano }\end{array}$ \\
\hline
\end{tabular}




\section{Quadro 2}

Perfil dos professores

\begin{tabular}{|l|l|l|l|}
\hline Participante & \multicolumn{1}{|c|}{ Formaçáo } & $\begin{array}{c}\text { Tempo de atuaçáo } \\
\text { profissional }\end{array}$ & $\begin{array}{c}\text { Tempo de atuaçáo na } \\
\text { instituiçáo de ensino das } \\
\text { estudantes }\end{array}$ \\
\hline Professor 1 & $\begin{array}{l}\text { Graduação em Pedagogia e Especializa- } \\
\text { ção em Psicopedagogia }\end{array}$ & 23 anos & 4 anos \\
\hline Professor 2 & Pedagogia & 2 anos & 2 anos \\
\hline $\begin{array}{l}\text { Educadora } \\
\text { Especial }\end{array}$ & $\begin{array}{l}\text { Especial. Especialização em TICs aplica- } \\
\text { das à Educaçáo e à Gestão Educacional e } \\
\text { Mestrado em Educação }\end{array}$ & 7 anos & 3 anos \\
\hline
\end{tabular}

\subsection{ProduÇáo De DAdOS}

Considerando os participantes e os objetivos da pesquisa, foram elencadas fontes múltiplas de evidência do estudo de caso proposto, por meio dos seguintes instrumentos para a produçáo de dados: entrevista focalizada e informaçóes documentais (atas de ocorrências escolares). Segundo Gil (2014), a entrevista focalizada é recomendada nos estudos exploratórios que investigam certos problemas em que "é importante que o pesquisado expresse livre e completamente suas opiniōes e atitudes em relação ao objeto da pesquisa, bem como os fatos e motivaçôes que constituem o seu contexto" (p. 111).

As fontes documentais utilizadas no estudo foram constituídas das atas de ocorrências escolares, que envolveram as estudantes em questáo, no ano letivo de 2019. Por atas escolares, entende-se todo e qualquer registro de acontecimentos, sejam eventos comportamentais, físicos, ou qualquer outra observação importante, que possa influenciar a vida escolar dos estudantes. As atas também podem descrever assuntos tratados em reuniōes com as famílias, sempre abordando a pauta e os acordos realizados entre os participantes. Geralmente, sáo escritas por um membro da equipe diretiva e assinada por todas as partes interessadas.

Para Gil (2010), as fontes documentais são variadas e numerosas, uma vez que qualquer elemento portador de dados pode ser considerado um documento. No Quadro 3, identificam-se tais documentos, referentes à Estudante 1 e à Estudante 2. 


\section{Quadro 3}

Informaçôes documentais referentes à Estudante 1 e à Estudante 2

\begin{tabular}{|l|l|l|l|}
\hline \multicolumn{1}{|c|}{ Atas } & \multicolumn{1}{|c|}{ Data } & \multicolumn{1}{c|}{ Motivo } & \multicolumn{1}{c|}{ Assinadas por } \\
\hline Atas 1, 2, 3, & Março a agosto/2019 & $\begin{array}{l}\text { Desmotivação para os estudos; presen- } \\
\text { ça de piolhos; queixas de sono e can- } \\
\text { saço; problemas de saúde; a máe não } \\
\text { responde aos chamados da escola; Con- } \\
\text { selho tutelar; angústias e medos relata- } \\
\text { dos pelas estudantes; encaminhamento } \\
\text { para o Ministério Público. }\end{array}$ & $\begin{array}{l}\text { Diretora da escola, vice-diretora, } \\
\text { coordenadora pedagógica, professor } \\
\text { 1, professor 2. }\end{array}$ \\
\hline Atas 6 e 7 & $\begin{array}{l}\text { Setembro a novem- } \\
\text { bro/2019 }\end{array}$ & $\begin{array}{l}\text { Acordos com o novo responsável legal, } \\
\text { percepçáo da melhora no desempenho } \\
\text { escolar das estudantes 1 e 2. }\end{array}$ & $\begin{array}{l}\text { Coordenadora pedagógica, professor } \\
\text { 1, professor 2, educadora especial, } \\
\text { responsável legal das estudantes 1 e 2 } \\
\text { (ex-padrasto). }\end{array}$ \\
\hline
\end{tabular}

Todos os procedimentos de produçáo de dados foram previamente amparados pelo Termo de Consentimento Livre e Esclarecido e Termo de Assentimento, devidamente aprovado pelo Comitê de Ética em Pesquisa da Universidade Federal de Santa Maria ${ }^{6}$, sob o número 053249 .

\subsection{ANÁlISE dos DADOS}

Bardin (2011) conceitua o termo análise de conteúdo como um conjunto de técnicas de análise de mensagens visando obter procedimentos sistemáticos e objetivos de descrição do conteúdo para se fazer inferências de conhecimentos relativos às condições de produção/ recepção dessas mensagens.

Entende-se que a análise de conteúdo proposta por Bardin (2011), por conter uma amplitude de técnicas capazes de contemplar diferentes contextos, permitiu o detalhamento e a riqueza de informações e descobertas, perpassando por informações muitas vezes resultantes do momento que se recolhe os dados e que podem adquirir um grau de contribuição relevante aos estudos e à solução do problema. As categorias de análise dos dados foram alinhadas aos sujeitos de pesquisa e ao que se pretendeu pesquisar. A partir da análise das entrevistas e dos documentos, evidenciaram-se três categorias, quais sejam: negligência familiar, aprendizagem de estudantes com DV e troca de guarda.

\section{Resultados E Discussóes}

A partir da leitura das atas e das entrevistas dos participantes, devidamente transcritas, que compóem a produção de dados deste estudo, e considerando as categorias de análise, os resultados foram compilados e alinhados a dimensóes teóricas, dispostos em três subseçóes conforme Figura 1.

\footnotetext{
${ }^{6}$ Refere-se que a pesquisa que aqui se apresenta seguirá os preceitos Éticos de Pesquisa com Seres Humanos, gerida pela Resoluçâo no 466, de 12 de dezembro de 2012, e devidos anexos, garantindo o sigilo das informaçóes prestadas pelos participantes. Este estudo integra um projeto mais amplo, denominado Educação, Saúde, Inclusão.
} 


\section{Figura 1}

Produção de dados e categorias de análise do estudo

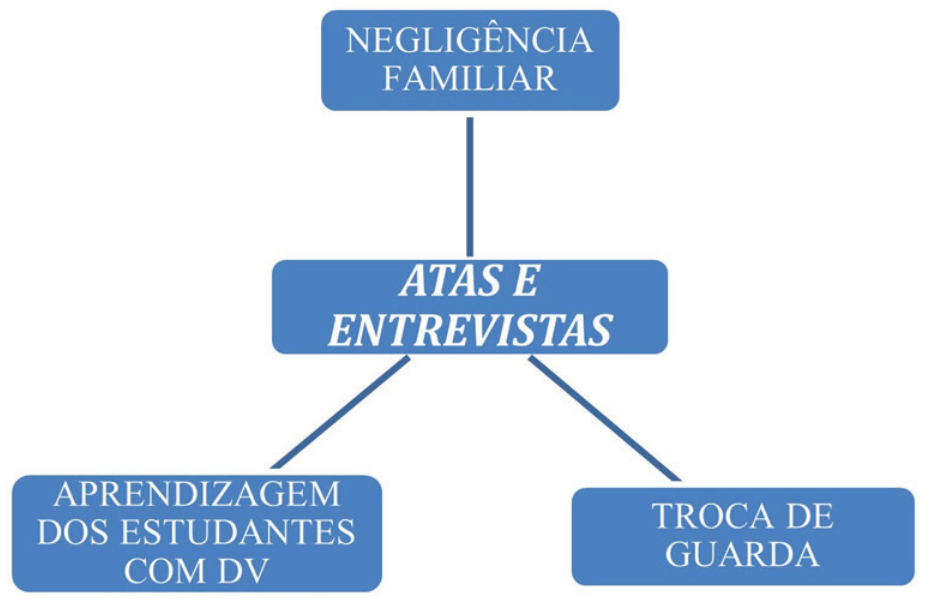

\subsection{NegLigÊNCIA FAMILIAR - O ABANDONO E A SUPRESSÃO DE NECESSIDADES BÁSICAS}

A primeira categoria elencada, negligência familiar, compôs o discurso das seis atas de ocorrência e das cinco entrevistas, analisadas para a produção de dados deste estudo. São situaçôes que ilustram a precariedade de atençáo e cuidados com as duas estudantes com deficiência visual, enquanto estavam morando com a mãe.

Entre as ocorrências da escola, referente às duas estudantes, aqui designadas Estudante 1 e Estudante 2, a primeira ata de 2019, trata do desinteresse da Estudante 2, do $5^{\circ}$ ano, pelas atividades escolares e da observação de piolhos, que atrapalham a menina. Sobre isso, a Educadora Especial, falando sobre a Estudante 2, relata que "era difícil dela se motivar para fazer alguma coisa. E daí tinha aquela questâo de fome, de frio, de piolho. Assim, o cabelo estava amarrado, mas o piolho caminhando em cima da cabeça". O Professor 1, em sua entrevista, também levanta essa questáo: "Ela parava todo momento de trabalhar porque tinha muito piolho na cabeça”.

Para Bridi Filho et al. (2018), "o sofrimento pode vir de várias formas (...). Pode ser expresso socialmente por meio do abandono, da desnutriçáo. O que está presente sempre, em todos os casos, é a percepção de um mundo hostil, agressivo e destrutivo" (p. 194). A negligência familiar ficou evidenciada também nas Atas 2, 3, 4 e 5, com temáticas como desmotivação para realizar as atividades escolares; queixas de sono e cansaço, tanto da Estudante 1 quanto da Estudante 2, falta de higiene, de rotina de sono, relatos das estudantes 1 e 2 de angústias e medos, e recorrentes tentativas de contato com a mãe, sem sucesso.

Sobre a desmotivação para as atividades escolares pelas estudantes, o Professor 1 e a Educadora Especial entrevistados dizem. "Ela já chegava emburrada, mais quieta, não queria fazer as atividades, ela simplesmente não fazia" (Professor 1); "Eu sentia bastante resistência, 
desânimo para fazer as atividades da escola, parece que nada estava bom, nada ela ficava satisfeita em fazer" (Educadora Especial).

"Eu tinha medo. Tipo, a mãe tava, a gente tava tudo deitado, alguém chamou ela. Bateu na porta, daí a mãe abriu e do nada e tipo era um cara e ele pediu dinheiro para ela assim do nada" (Estudante 2). Esses comportamentos apresentados pelas estudantes podem configurar uma reação às condiçôes de negligência familiar, uma vez que "expressóes de raiva, isolamento, frieza emocional ou agressividade no trato social, podem aparecer na infância em comportamentos reativos, de luta ou oposição desafiante (...)” (Bridi Filho et al., 2018, p. 189).

A falta de rotina de sono também foi um fator presente nas atas e nas entrevistas. Para Pereira et al. (2018), o desempenho diurno de uma criança, tanto na escola quanto em outros ambientes, está diretamente ligado à qualidade de seu sono. Problemas de sono geram a diminuição à atenção e à concentração, afetando a memória e, consequentemente, o aprendizado.

As estudantes trouxeram esse aspecto em suas falas: "Nós tinha uma cama que nós dormia muito mal" (Estudante 1). E a Estudante 2 completa: "Eu não conseguia dormir, que todos os final de semana, ligavam o som de noite, e eu não conseguia dormir" (Estudante 2). Sobre isso, o Professor 1, referindo-se à Estudante 1, diz que:

Chegava com sono, não dormia direito porque dormia na mesma cama com a irmã. A mãe, segundo ela, passava, a noite vendo filme, ouvindo música. [...] cruzava os braços e dizia que tava com dor, dor de cabeça, dor de barriga e sono, escorava a cabeça e dormia na sala de aula, literalmente. Ela conta que, às vezes, a mãe tinha brincado a noite toda com dois homens na cama, que é uma coisa bem difícil da gente ouvir. (Professor 1)

"A privação do sono gera fadiga, irritabilidade, alteraçóes no rendimento das tarefas diárias e comprometimento nas relaçóes interpessoais" (Pereira et al., 2018, p. 77). Assim, evidenciam-se questóes que prejudicam todas as dimensões da infância, confirmando a gravidade e a indiscutível falta de cuidado e atenção às necessidades das estudantes.

A alimentação é outro fator de destaque na situação das estudantes. Referindo-se à Estudante 1, o Professor 1 afirmou:

Nós esbarramos nas questóes da família, que peca no estímulo, necessidades alimentares, necessidades de carinho, necessidades de higiene [...], vinha com cheiro forte de xixi, pouca roupa no inverno, calçado pequeno para o tamanho do pé, muita fome. Nós tivemos um passeio ao quartel e o lanche acabou acontecendo mais tarde, em função das atividades e ela acabou desmaiando de fome. (Professor 1)

\section{Sobre a Estudante 2, a Educadora Especial relatou:}

Então essas coisas assim foram as mais difíceis e claro uma criança com fome, uma criança com frio, uma criança todo momento se coçando. A estudante 2 ainda tem problema de furúnculos. Esse ano, um furúnculo na boca, já teve furúnculo no bumbum, não podia se sentar. Era tudo muito difícil pra ela, a roupa suja, o rosto sujo de manhá, não tinha escovado os dentes [...]. (Educadora Especial) 
"A mãe, às vezes não dava café, às vezes ela xingava a gente" (Estudante 1). "Ela não dava café sabe, para gente, de manhã. $\mathrm{O}$ telefone não despertava, ou às vezes, ela não queria levantar. Tinha bastante tempo ali e ela não fazia café” (Estudante 2). A respeito disso, é possível perceber, de forma pontual, os efeitos dessa negligência e os possíveis comportamentos decorrentes de tal situação. $\mathrm{O}$ medo aparece como resposta e a criança perde a sua capacidade de diferenciar entre perigo e segurança e passa a reconhecer como ameaça as situaçóes em ambientes não ameaçadores (Bridi Filho et al., 2018).

Nesse cenário, a escola, como agente social, cumpriu seu papel de registrar essas ocorrências, fazer o chamamento à família, representada pela figura materna, e fazer os encaminhamentos legais - Conselho Tutelar e Ministério Público. Apesar disso, a aprendizagem escolar das duas estudantes foi tocada por todas essas situaçóes.

\subsection{A APRENDIZAGEM ESCOLAR E A DEFICIÊNCIA VISUAL: REFLEXOS DA NEGLIGÊNCIA FAMILIAR}

Para Sá et al. (2007), "os estudantes com deficiência visual, sejam eles cegos ou baixa visão, apresentam as mesmas potencialidades para a aprendizagem do que os demais, pois a deficiência visual não o torna incapaz, não limita a sua capacidade de aprendizado" (p. 37).

Nas entrevistas, a questão da aprendizagem das estudantes com $D V$ e a visão pedagógica da escola ficaram evidenciadas. O Professor 1 falou um pouco sobre a prática pedagógica com a Estudante 1:

Então, eu comecei a estudar, fui atrás do Braille, de como trabalhar a matemática. O mínimo de recursos a gente tem. A máquina Perkins, para ela poder acompanhar as aulas; então, se os colegas escreviam uma frase, ela fazia a frase em Braille, acompanhava toda a aula, entáo lia o texto, e ela fazia toda a interpretação no Braille. A matemática, a gente trabalhava sempre com material dourado. Num outro momento, a gente sentiu a necessidade do Sorobã. A escola disponibilizava esse material disponibiliza até hoje. Tanto ela quanto a irmã têm um monitor, que facilita bastante porque daí então eu posso atender à turma, e quando ela precisa de apoio, o monitor dá esse apoio específico, né, no caso do aluno. Além disso, a gente faz as adaptaçôes em casa. [...] é importante ficar claro assim, que as atividades náo eram feitas para as meninas com $\mathrm{DV}$, as atividades que elas fazem são as mesmas atividades que as da turma. Então, assim, se eu passo um mapa, elas recebem um mapa tátil, se nós fazemos gráficos e tabelas, elas recebem os gráficos e tabelas adaptadas. (Professor 1)

\section{Sobre o acompanhamento dessas atividades, o Professor 2 apontou:}

Bom, eu conheço as estudantes anteriormente à escola, na instituição que elas fazem o atendimento de apoio. Em casa, elas não tinham quem desse suporte para elas. De fazer a cobrança por exemplo: de ela escrever, ou fazer a cobrança da leitura dos temas, da leitura de alguma coisa, dar um apoio em casa. Desde o início do ano, ela relatava coisas que aconteciam em casa, e isso a gente via que acabava afetando um pouco o desenvolvimento dela. A mãe dizia que não era importante ela estudar, nem saber o Braille, porque sempre ia ter alguém na família junto. (Professor 2)

Entende-se que "o cuidar da criança não é uma conduta isolada, mas sim intrínseco ao mundo em que a mãe vive, de obrigaçóes, incertezas, inseguranças, desejos, sonhos, um contexto familiar, ou seja, uma experiência de vida, única, subjetiva, com significado individual” 
(Frota \& Oliveira, 2004, p. 163). No entanto, mesmo levando em conta todos esses aspectos, a negligência familiar é explícita no caso dessas estudantes. Confirmando a ausência da mãe, no acompanhamento das atividades escolares, o Professor 1, referindo-se à Estudante 1, contou:

Ela tem uma pasta para fazer os registros da aula, em Braille. Ela tinha uma pasta do primeiro trimestre e uma pasta do segundo trimestre. Então a pasta do $2^{\circ}$ trimestre voltou um dia na mochila, eu peguei a pasta toda rasgada, com cocô de bicho e as folhas todas rasgadas. Eu coloquei dentro de uma sacola e guardei. Quando o Conselho Tutelar veio, eu mostrei essa pasta rasgada, ela disse que foi a mãe, que o cachorro fez cocô, enfim. (Professor 1)

E a Educadora Especial, sobre a Estudante 2, completou:

Eu percebi assim, o que ela escrevia levava para casa, mas ela náo fazia leitura e eu percebi que não tinha estímulo em casa para fazer isso. Então, o material voltava todo bagunçado, sujo. Se ela tivesse um acompanhamento ela iria fazer e não estaria assim. Teve uma vez que ela derramou óleo em uma pasta, com todos os trabalhos do final do ano de 2018. Ela voltou no início de 2019 com uma pasta que estava totalmente encharcada de óleo de cozinha. (Educadora Especial)

Esses relatos ilustram a falta de estímulo da família no acompanhamento das atividades escolares das estudantes com DV. "Ela só queria ficar com o namorado dela. Tipo, a mana falou; 'mãe, tem tarefa', daí ela falou bem assim: 'mas não precisa fazer hoje'. Ela falou bem assim para ela" (Estudante 2). "Eu acho que a Estudante 1 poderia estar lendo, coisa que ela ainda não faz em função de tudo isso" (Professor 1). Sobre isso, Buscaglia (2006) afirma que a família guiará a criança na luta para o desempenho de seu papel de ser humano. As atitudes da família em relação à criança terão influência significativa sobre as atitudes pessoais. Os sentimentos da família em relação à deficiência afetarão diretamente os sentimentos da criança a esse respeito.

Assim, a interação com a mãe, seja verbal ou não verbal, é primordial para o desenvolvimento motor, linguístico e social da criança, uma vez que a exploração do ambiente para a pessoa com deficiência visual é mais limitada e vai depender de oportunidades oferecidas (Medeiros \& Salomão, 2012). Desse modo, no caso de estudantes com deficiência visual, o desempenho do papel parental é fundamental para a aprendizagem e o acompanhamento das atividades escolares, significando, diretamente, no sucesso ou náo da caminhada educativa dos estudantes.

\subsection{A TROCA DE GUARDA - UMA NOVA PERSPECTIVA}

A terceira categoria elencada para análise foi a troca de guarda das estudantes, ocorrida em meados de setembro de 2019. Essa categoria está presente nas Atas 6 e 7 e nas entrevistas.

$\mathrm{Na}$ Ata 5, em agosto de 2019, após os relatos de todos os fatos anteriormente narrados, e o acompanhamento do conselho tutelar no caso das irmãs, ficou registrado, pelos dois conselheiros tutelares, a necessidade de retirada da guarda da mãe. Foi sugerido, pelos profissionais da instituiçáo escolar, o ex-padrasto como possível responsável legal, uma vez que as meninas o consideravam como pai, pois nunca tiveram contato com o pai biológico. Segundo consta na ata, todas as vezes que fora chamada a família em anos anteriores, o padrasto compareceu. Conduto, em 2019, com a separação do casal, a situação das crianças chegou ao extremo. O pai (ex-padrasto) aceitou a guarda provisória das duas meninas com deficiência visual. 


\section{O Professor 1 contou a angústia de conviver com a negligência da família:}

Faz 2 meses que ela está com o padrasto e todo o restante do ano, 7 meses, que ela esteve com a máe, foi um ano perdido na aprendizagem dela. A gente escuta criança, e o que que acontecia? Nós começamos a chamar a família para tentamos conversar, mas as ligaçôes não eram atendidas, então a mãe passou a não atender os números da escola, nem das professoras, nem da coordenação, mandamos bilhete pelo caderno, os bilhetes não vinham assinados. As meninas relataram que a mãe lia os bilhetes, mas não assinava. Então a gente passou a não ter mais contato com a família, a mãe delas que tinha a guarda. Elas vinham e voltavam de van, enviamos recado pelo senhor que dirigia a van, pedimos para mãe vir, a mãe não vinha, não vinha, não vinha. (Professor 1)

Sobre a troca de guarda, o Professor 2 relatou que, no dia seguinte, quando a Estudante 2 chegou e foi perguntada sobre a "casa nova", respondeu: "Eu tô bem feliz, tava com saudade do pai”. Outras falas também impactam a leitura da transcrição das entrevistas, sobre o novo lar: "A gente toma banho todos os dias e tem até escova de dente" (Estudante 2). "O pai conversa com a gente, ele, ele brinca com a gente. Ele fala bem assim: gurias, vai fazer os temas" (Estudante 1). Para Bridi Filho et al. (2018), “o prejuízo pode ser revertido em algumas situaçôes mediante experimentação de novas formas de interação sem o uso da violência” (p. 190).

Segundo a Educadora Especial, depois da troca de guarda, "as meninas vieram mais limpas, o cabelo estava limpo, estavam alimentadas”. O Professor 1, referindo-se à Estudante 1, disse que:

A partir do momento que ela está com esse padrasto, que é uma pessoa que tem uma boa vontade, eu acho que entáo a gente tem que aproveitar isso. A gente já viu que elas foram limitadas em função da negligência e a partir de agora é trabalhar esse novo momento em família. Então esse pai agora impóe alguns limites, impóe limite de horário e eu acho que agora tá o papel da escola fortalecer esse relacionamento, e fazer com que elas entendam que isso é bom para elas e elas estáo crescendo com isso. (Professor 1)

\section{O Professor 2, referindo-se à estudante 2, emendou:}

Depois da mudança da guarda é como se tivesse entrado outra criança na sala de aula. Uma menina mais motivada, que começou a perceber a importância dos estudos, que dá abertura para tu trazer os conteúdos. E quando não está dando certo, ela fala que não está dando certo, coisa que até a metade desse ano eu jamais vi. Por exemplo, ela disse "não tô conseguindo entender", coisa que antes não fazia, não esboçava reação. (Professor 2)

Segundo afirmam Medeiros e Salomão (2012), a participação da família é fundamental até mesmo no planejamento das intervenções a serem realizadas com a criança. Para tanto, a troca de guarda, ainda que recente, vem se constituindo em uma alternativa contra o descaso ao qual as estudantes estavam expostas.

\section{CONSIDERAÇÓES FINAIS}

Por meio da observação das evidências de negligência familiar com duas meninas cegas, no cenário de uma escola pública municipal, localizada em uma comunidade carente, este 
estudo investigou as interferências de tal situação em relação aos processos de aprendizagem de estudantes com deficiência visual.

Os objetivos do estudo foram alcançados na medida em que o estudo de caso, delineamento adotado, foi sendo desenvolvido. A produção de dados contou com duas fontes de evidência: sete atas de ocorrências escolares referentes as duas estudantes com deficiência visual, que são irmãs, e entrevista focalizada de seus professores de classe e da educadora especial. Assim, apresentam-se as consideraçôes relacionadas à produção de dados do estudo e as contribuiçóes.

A análise permitiu destacar categorias que sinalizam as conclusóes mais importantes do estudo. A negligência familiar é de difícil identificação, os fatos íntimos, as pequenas coisas que ocorrem no interior de um lar, podem jamais serem conhecidas. Entretanto, quando são desvelados acontecimentos que podem sugerir a negligência, apontando casos graves, com situaçóes que interferem sobremaneira nas atitudes, nas relaçóes e nos sentimentos dos que vivem essa realidade, muitas vezes, somente medidas judiciais podem conter tal negligência.

Quando se trata de crianças com deficiência, torna-se ainda mais grave a situação, pela condição de vulnerabilidade que impóe a infância e a condição de deficiência. A negligência familiar causa danos perceptíveis na relação e na interação com o mundo exterior, na saúde e no bem-estar, prejudicadas pela falta de cuidados físicos, no controle emocional e na motivação para os estudos.

A vida escolar das estudantes com DV apresentadas neste estudo, antes de questóes inclusivas e pedagógicas que atendessem e promovessem uma aprendizagem satisfatória, foi impactada pela supressão de direitos fundamentais, sendo necessário o uso de medidas judiciais para que as meninas tivessem garantido o seu direito de estar na escola em prontidão para aprender.

As expectativas de sucesso escolar caem consideravelmente para os estudantes que são sujeitos a maus tratos e negligências de toda ordem, por suas famílias, uma vez que esta oportuniza as primeiras aprendizagens e impacta a conduta e a percepçáo dos estudantes com deficiência visual, na qualidade de pessoas ativas e potentes.

A terceira categoria da análise, troca de guarda, apontou que, ao cessar as situaçóes de negligência familiar e os processos destrutivos dessa situação, com a retirada da guarda da mãe, as estudantes com DV puderam experimentar uma nova expectativa de vida. Um lar seguro, o apoio e o respeito aos seus direitos fundamentais, foi algo que pode renovar as chances e as possibilidades dessas estudantes.

Assim sendo, ao trazer os dados da referida pesquisa, este estudo inova em conceitos e ideias no campo da Educação especial, trazendo avanços, a partir do momento que, associando fatos reais do cotidiano de estudantes com DV, analisa os acontecimentos e seus encaminhamentos, à luz do conhecimento científico da área e aponta a importância da intervenção em contextos específicos, como o descrito na pesquisa. No entanto, é preciso considerar que a pesquisa aborda as condiçóes em que estudantes com DV convivem sob a égide da negligência familiar, no contexto escolar. Aprofundar os estudos sobre a temática em outros contextos poderá trazer novas contribuiçóes. 
Este estudo convida a acreditar que, voltando à escola, as meninas estarão agora com suas necessidades físicas atendidas e com a expressão de quem acredita em si e sabem que, ao final do turno, voltarão para a família que as aceitou e acolheu. É possivel as ver caminhando no pátio da escola, parecem felizes... teria sido o novo lar? Teria sido as novas aprendizagens? As cenas não denotam, nem ao longe, a negligência sofrida...

\section{REFERÊNCIAS}

Bardin, L. (2011). Análise de conteúdo. Ediçôes 70.

Bridi Filho, C. A., Bridi, F. S. R., \& Tavares, L. R. G. (2018). Abuso e negligência na infância: efeitos neurobiológicos na aprendizagem. In N. T. Rotta, C. A. Bridi Filho, \& F. R. S. Bridi (Orgs.), Plasticidade cerebral e aprendizagem: abordagem multidisciplinar (1 $1^{\text {a }}$ ed., pp. 182-195). Artmed.

Bruno, M. G., Bruno, M., \& Mota, M. G. B. (2001). Programa de Capacitação de Recursos Humanos do Ensino Fundamental: deficiência visual. Brasília: Ministério da Educação, Secretaria de Educação Especial.

Buscaglia, L. (2006). Os deficientes e seus pais. Record.

Constituição Federal da República Federativa do Brasil (1988). Brasília, DF. Recuperado em 20 de novembro de 2019 de https://www2.senado.leg.br/bdsf/bitstream/handle/id/518231/CF88_ Livro_EC91_2016.pdf

Frota, L. M. C. P., \& Oliveira, V. L. M. (2004). A experiência de ser mãe da criança com paralisia cerebral no cuidado cotidiano. Revista Brasileira de Educação Especial, 10(2), 161-174.

Gil, A. C. (2010). Como elaborar projetos de pesquisa. Atlas.

Gil, A. C. (2014). Métodos e técnicas de pesquisa social. Atlas.

Lei no 8.069, de 13 de julho de 1990. Dispóe sobre o Estatuto da Criança e do Adolescente e dá outras providências. Recuperado em 20 de novembro de 2019 de http:/www.planalto.gov.br/ CCIVIL_03/leis/L8069.htm

Lei no 9.394, de 20 de dezembro de 1996.Lei de Diretrizes e Bases da Educação Nacional Estabelece as diretrizes e bases da educaçáo nacional. Recuperado em 20 de novembro de 2019 de http://www. planalto.gov.br/ccivil_03/LEIS/L9394.htm

Lima, P. A. L. (2005). O aluno com deficiência visual na escola. In Secretaria da Educação de Minas Gerais (Ed.), Veredas - Formação superior de professores: módulo 7 (v. 3). SEE-MG.

Lima, D. M. C. (2006). A educação infantil: saberes e práticas da inclusão. Brasília: Ministério da Educação, Secretaria da Educação Especial.

Machado, A. P. R., \& Pereira, J. L. C. (2019). O lúdico na formação de conceitos: o brincar da criança com cegueira congênita. In A. C. O. Pavão, \& S. M. O. Pavão (Orgs.), Práticas educacionais inclusivas na educação básica (1ª ed., pp. 47-65). Facos - UFSM.

Medeiros, C. S., \& Salomão, N. M. R. (2012). Concepçôes maternas sobre o desenvolvimento da criança deficiente visual. Revista Brasileira de Educação Especial, 18(2), 283-300. 
Oliveira, A. R. P., Munster, M. A., \& Gonçalves, A. G. (2019). Desenho Universal para Aprendizagem e Educação Inclusiva: uma Revisão Sistemática da Literatura Internacional. Revista Brasileira de Educação Especial, 25(4), 675-690.

Pereira, T. C. A., Guardiola, A., \& Porciuncula, R. A. L. (2018). Problemas do sono nos transtornos neurológicos e psicológicos. In N. T. Rotta, C. A. Bridi Filho, \&, F. R. S. Bridi (Orgs.), Plasticidade cerebral e aprendizagem: abordagem multidisciplinar (1'a ed., pp. 56-80). Artmed.

Resolução no 466, de 12 de dezembro de 2012. Recuperado em 3 de dezembro de 2019 de https://bvsms. saude.gov.br/bvs/saudelegis/cns/2013/res0466_12_12_2012.html

Sá, E. D., Campos, I. M., \& Silva, M. B. C. (2007). Atendimento Educacional Especializado-Deficiência Visual. SEESP / SEED / MEC. Recuperado em 20 de novembro de 2019 http://portal.mec.gov.br/ seesp/arquivos/pdf/aee_dv.pdf

Yin, R. K. (2015). Estudo de caso: planejamento e métodos. Bookman.

Recebido em: 31/01/2020

Reformulado em: 18/07/2020

Aprovado em: 17/10/2020 